\title{
Balancing Depth with Breadth: a Metacomunicative Perspective on the ViSA Group Analysis of Common Data
}

\author{
Wendy Leeds-Hurwitz
}

\section{(2) OpenEdition Journals}

Electronic version

URL: https://journals.openedition.org/educationdidactique/1540

DOI: $10.4000 /$ educationdidactique. 1540

ISSN: $2111-4838$

Publisher

Presses universitaires de Rennes

\section{Printed version}

Date of publication: 30 November 2012

Number of pages: 157-160

ISBN: 978-2-7535-2254-1

ISSN: 1956-3485

\section{Electronic reference}

Wendy Leeds-Hurwitz, "Balancing Depth with Breadth: a Metacomunicative Perspective on the ViSA Group Analysis of Common Data", Éducation et didactique [Online], 6-3 I novembre 2012, Online since 30 November 2014, connection on 14 September 2022. URL: http://journals.openedition.org/ educationdidactique/1540 ; DOI: https://doi.org/10.4000/educationdidactique.1540 


\title{
BALANCING DEPTH WITH BREADTH: A METACOMUNICATIVE PERSPECTIVE ON THE VISA GROUP ANALYSIS OF COMMON DATA
}

\author{
Wendy Leeds-Hurwitz (University of Wisconsin-Parkside)
}

\begin{abstract}
The advantages and disadvantages of group analysis of common videotape data are considered. Key issues explored relate to the amount of context required to interpret behavior; the emphasis placed on re-examination of the original videotape versus the transcript; and the impact of participants' prior research experiences upon their interpretation of behavior as significant. Multiple analyses of the same data highlight the fact that theoretical and methodological frameworks always influence what analysts see and select as worthy of attention, as well as influencing the resulting analysis.
\end{abstract}

Keywords: metacommunication, videotapes, methodology, interaction analysis, classroom interaction, ethnographic present.

Wendy Leeds-Hurwitz

What I can bring to this discussion is a US perspective on analyzing videotape data, as practiced by Communication scholars, especially ethnographers of communication, in order to frame my discussion of what occurred at the ViSA group analysis of data.Interaction scholars in the US have been engaging in multiple analyses of common data for many years. I have experienced instances of carefully preparing analyses ahead of time (usually as a full-day preconference as part of an annual conference), but also sessions where participants contributed opinions more informally, either during a single panel at a conference where data is shown and opinions solicited on the spot, or as a way to further research in an ongoing long-term project by bringing in colleagues from another research team, department, or university.

Cooren (2007) is the most complete example I know, because that effort culminated in publication, whereas most such conversations are more informal. This book resulted from a preconference at the International Communication Association (ICA) convention in 2001, co-sponsored by two divisions: Language and Social Interaction, and Organizational Communication, as a way to explore potential overlapping interests. Participants were sent a copy of the Canadian documentary film Corporation: After Mr. Sam as well as a transcript of the film ahead of time. The selection of data led to some discussion of the value of a documentary as data, as well as discussion of the management meeting it recorded, but most importantly, it led researchers accustomed to drawing on different methodological and theoretical assumptions to make these explicit for themselves and others, and begin to compare advantages and disadvantages of each.

This was the most complete version of the process, but certainly there were predecessors. I participated in several earlier iterations of preconferences sponsored by the Language and Social Interaction division of ICA as a way to spark conversations just among division members, who typically were taking very different approaches to data and analysis, and who otherwise read and talked mostly with those taking comparable approaches to comparable data. That is, those who define themselves as ethnographers of communication typically talked with others using the same method; those who emphasize classroom ethnography typically talked with others studying the same domain. Sometimes transcripts were circulated ahead of time, but often each participant transcribed the same videotaped data prior to their analysis. In either case, these conversations frequently resulted in discussions of what elements required transcription (only verbal comments, or some combination of paralinguistic, kinesic, and proxemic behaviors as well). These discussions often showed the large gap in what was taken for granted across the group and led to fascinating conversations and new or substantially revised research projects.

At least in my memory, there were always conflicts when the preconference participants came together to compare their analyses. Typically the most controversial aspect concerned the extent to which, and how much, context was required 
to interpret behavior. When a group of disparate scholars all work on the same small segment of data, obviously few will have been part of the data collection effort, and so most of those analyzing the data will not have the opportunity to have learned much about the context surrounding that data segment. What happened before the interaction that was recorded, what resulted from it, what other roles did these participants play, is this interaction typical - these questions all require some knowledge of the larger context. Concern for the implications of context for analysis varies by analytical approach: for some participants this was a significant issue, but for others it mattered not at all. Typically the ethnographers in the preconferences wanted considerable contextual data, but the conversation analysts and ethnomethodologists assumed that everything they needed to know was evident in the interactional moment captured on videotape.

The emphasis placed on the original film versus the transcript became a second potential area of conflict. Examination of the former permits inclusion of nonverbal behaviors that were entirely or largely omitted from the latter. Again, there were variations by methodological and theoretical orientation of the participants in the conversation. In this case also, the largest divide in our conversations in the US tended to separate ethnographers from conversation analysts, with the former more likely to want to incorporate at least some nonverbal aspects of the interaction, and the latter more likely to focus on words. The question really centers around whether analysis should emphasize what occurs in the videotape, or just in the transcript of what occurs in the videotape. To take full advantage of the possibilities offered by videotape implies paying attention to more than just words, which probably requires attending to the videotape and not only the transcript.

What caught different analysts' attention as interesting, relevant, and worthy of analysis in the data also varied substantially depending on their prior research, so this served as the final issue raised in these meetings. Each participant's prior research investigations into specialized topics (whether laughter or interruptions, politeness or questions, teaching or learning, hidden agendas or co-construction of knowledge) meant that it was always easy for that researcher to notice detailed moments in the data that completely escaped the attention of others. This was a good example of the way past experience influences what we see as significant, not only as participants in interaction but even as analysts.

Let me now pull back from the US examples of multiple analyses of the same data in order to make some more general comments about this particular ViSA data session. Having a group of scholars analyze the same data meets the goal of obtaining different analytic perspectives on the data. In practice, this goal may be difficult to accomplish due to the potential threat to face concerns - who wants to hear that they missed something critical that others consider obvious? Yet the goal remains worthwhile: bringing new analytic techniques to a group opens up conversations about assumptions that otherwise may remain unspoken.

Multiple analyses of the same data highlight the fact that theoretical and methodological frameworks always influence what analysts see and select as worthy of attention, as well as influencing the resulting analysis. In my experience, the hardest thing to teach, and sometimes the hardest thing to remember myself, is the distinction between data and analysis - what people can be observed to do is just not the same as how we interpret their behavior. We all unconsciously read more into what we see than what is there, and must learn to separate out connotation from action or words. A related point is that each researcher develops a particular approach to data, but that approach needs to be understood as only one possibility drawn from a larger set of possibilities. Asking a group of scholars to analyze the same data highlights their different approaches and what they bring to the analysis, even when studying the same basic research question and/or using the same data. In fact, sometimes these circumstances make differences especially visible.

To me, the central research question when analyzing classroom interaction is always some variation of the following key question: How do this teacher and these students jointly construct what occurs? So the issues always converge around the co-construction of learning. This question actually has two very different aspects: 
a. What do teachers do, and what is this particular teacher doing in this particular case, to encourage and permit learning to occur?

b. What do students do, and what do these particular students do in this particular case, to learn something new and then to demonstrate their learning?

The didactic contract discussed by Tiberghien describes just this, asking: what are the expectations in this particular classroom necessary for learning to occur? The didactic contract then serves as the basis for all the activities occurring within a particular classroom, grounding the relationships established and maintained over the school year. One matter open to investigation will always be whether all participants in a classroom are operating under the same set of assumptions - since most of the guidelines are unspoken, they may not always be the same, and participants may not even recognize their misunderstandings. Lima looks at deictic terms and how they are used, a narrow focus, while Zaid looks at the influence of teaching on student learning, a broad focus. Talbot and Arrieu-Mutel consider local context, while Chopin considers local time. Together all of these approaches can be described as the requisite local knowledge participants bring to the interaction (which analysts who are non-participants must work hard to understand).

Overall, like all research techniques, group analysis of common data provides both advantages and disadvantages. Coming to a shared sense of the range of approaches that can be taken to analyze data provides the most important benefit to group members. Other benefits include: 1) providing training for new group members in the methods already in use by others; 2 ) building a community of practice around a shared set of methodological and theoretical assumptions, as well as developing vocabulary useful to discussing these; and 3) discovering previously unrecognized research overlaps among group members.

The primary disadvantage results from inadequate knowledge of context for those who incorporate context into their analysis, including a good sense of how local participants interpret this behavior in this context, so that some of the complexity of interaction may be lost. A related loss may be a clear understanding of all of the activities in one classroom and the relationships between them. At the same time, the gain here is a comparative sense of interactions across classrooms resulting from viewing data collected by others. Losing a sense of the trajectory of activities within a classroom means not being able to take that group's past and present into account. The parallel gain permits a larger understanding of what Ray Birdwhistell called the "ethnographic present" - collapsing activities that occur over time in order to magnify interaction in the present moment. As Halstead (2008) explains, "The ethnographic present escapes 'ordinary historical categories' by emerging within and through the transformative spaces of anthropological knowledge construction" (p. 3). Small variations in actual examples from the past and present are less a concern than understanding the structure of how interaction occurs in a particular context, for a particular group.

Given that gains are accompanied by losses, it would be impossible to recommend that group analysis of common data (providing breadth) ever be substituted for individual analysis of each research team's data (providing depth). But given that losses are accompanied by gains, it is important that efforts to open data to wider analysis across a group such as ViSA continue. The goal must be to balance depth with breadth. Each form of analysis provides different insights, and both are valuable. Luckily, they are not exclusive, but complementary. 


\section{REFERENCES}

Cooren, François. (Ed.). (2007). Interacting as organizing: Analyses of a management meeting. Mahwah, NJ: Lawrence Erlbaum.

Halstead, Narmala. (2008). Introduction: Experiencing the ethnographic present: Knowing through 'crisis.' In Narmala Halstead, Eric Hirsch \& Judith Okely (Eds.), Knowing how to know: Fieldwork and the ethnographic present (pp. 1-20). New York: Berghahn Books. 